\title{
LASER SURFACE MELTING OF SINTERED AISI T15 HIGH-SPEED STEEL
}

R. VILAR, R. SABINO and M. ALMEIDA

Instituto Superior Técnico and CEMUL, Av. Rovisco Pais, P-1096 Lisboa, Portugal

\begin{abstract}
Samples of AISI T15 high speed steel produced by powder metallurgy were melted using $\mathrm{CW} \mathrm{CO}_{2}$ laser radiation. The power density and the interaction time were varied in the ranges $7 * 10^{4}-10^{5} \mathrm{~W} / \mathrm{cm}^{2}$ and 0.06 to $0.25 \mathrm{~s}$, respectively.

The microstructure of the sintered steel consisted of $M_{6} C$, $M C$ and $M_{23} C_{6}$ carbides in a bainitic matrix. Some samples were quenched in order to produced a martensitic structure. The density of pores was about $50 \mathrm{~cm}^{-2}$ and their mean size was $35 \mu \mathrm{m}$. After the laser treatment, the roughness of the surface was moderate $(1<\mathrm{Ra}<2 \mu \mathrm{m})$ and no defects were detected. The depth of the melted layer was higher for the quenched samples than in the as-sintered condition. Its microstructure was cellular, with martensite, retained austenite and a small fraction of $M_{6} C$ and $M C$ carbides. The residual porosity was completely eliminated. The microhardness of the laser treated material was high $(800<H V 0.1<1000)$. Its value increased with decreasing cell diameter and, hence, with increasing laser power and decreasing interaction time.

Laser surface melting seems to be an effective technique to eliminate the porosity of sintered steels and hence, increase their toughness and cutting performance.
\end{abstract}

